\title{
Corrigendum: Climate Risk Assessment under Uncertainty: An Application to Main European Coastal Cities
}

\author{
Luis M. Abadie, Elisa Sainz de Murieta * and Ibon Galarraga \\ Basque Centre for Climate Change, Leioa, Spain
}

Keywords: uncertainty, sea-level rise, coastal flooding, economic losses, risk measures, cities

\section{OPEN ACCESS}

Edited and reviewed by: Iñigo J. Losada,

University of Cantabria, Spain

*Correspondence:

Elisa Sainz de Murieta elisa.sainzdemurieta@bc3research.org

Specialty section:

This article was submitted to Ocean Engineering, Technology, and

Solutions for the Blue Economy, a section of the journal Frontiers in Marine Science

Received: 03 June 2017 Accepted: 16 June 2017

Published: 11 July 2017

Citation:

Abadie LM, Sainz de Murieta E and Galarraga I (2017) Corrigendum:

Climate Risk Assessment under Uncertainty: An Application to Main European Coastal Cities.

Front. Mar. Sci. 4:211. doi: 10.3389/fmars.2017.00211

\section{A corrigendum on}

Climate Risk Assessment under Uncertainty: An Application to Main European Coastal Cities by Abadie, L. M., Sainz de Murieta, E., and Galarraga, I. (2016). Front. Mar. Sci. 3:265. doi: 10.3389/fmars.2016.00265

In the originally published article, the first line of the sub-section "Future Projections of Sea-Level Rise at City Level" in page 2 says:

"Global sea-level has risen by more than $20 \mathrm{~cm}$ since 1980 (Hardy and Nuse, 2016) and the rate of SLR during the twentieth century is estimated to have been $1.7 \pm 0.3 \mathrm{~mm}_{\text {year }}{ }^{-1}$ (Church and White, 2006, p. 2)."

The reference year of global sea-level rise should be replaced as shown next:

"Global sea-level has risen by more than $20 \mathrm{~cm}$ since $\mathbf{1 8 8 0}$ (Hardy and Nuse, 2016) [...]"

\section{REFERENCES}

Hardy, R. D., and Nuse, B. L. (2016). Global sea-level rise: weighing country responsibility and risk. Clim. Change 137, 333-345. doi: 10.1007/s10584-016-1703-4

Conflict of Interest Statement: The authors declare that the research was conducted in the absence of any commercial or financial relationships that could be construed as a potential conflict of interest.

Copyright (C) 2017 Abadie, Sainz de Murieta and Galarraga. This is an open-access article distributed under the terms of the Creative Commons Attribution License (CC BY). The use, distribution or reproduction in other forums is permitted, provided the original author(s) or licensor are credited and that the original publication in this journal is cited, in accordance with accepted academic practice. No use, distribution or reproduction is permitted which does not comply with these terms. 